\title{
Access to Water Resources and Household Vulnerability to Malaria in the Okavango Delta, Botswana
}

\author{
M. R. Motsholapheko and B. N. Ngwenya
}

\section{Contents}

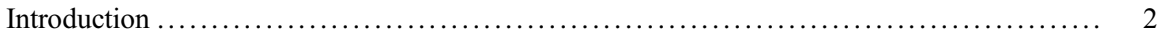

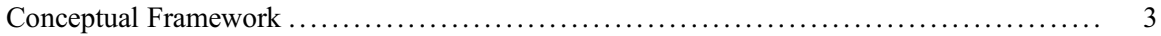

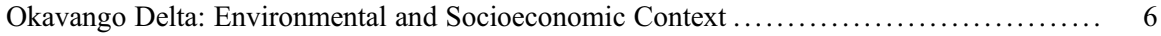

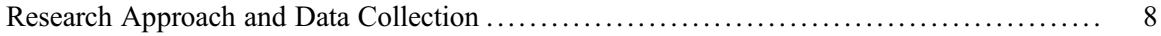

Participatory Rural Appraisal (PRA) Workshop ............................... 8

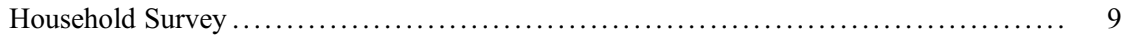

Access to Water Resources in Shakawe and Ngarange ............................. 10

Household Vulnerability to Malaria in Shakawe and Ngarange ..................... 12

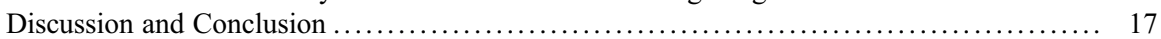

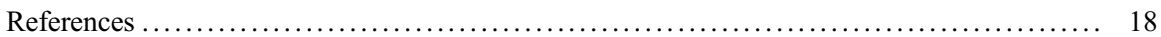

\section{Abstract}

Malaria is a persistent health risk for most rural communities in tropical wetlands of developing countries, particularly in the advent of climate change. This chapter assesses household access to water resources, livelihood assets, and vulnerability to malaria in the Okavango Delta of north-western Botswana. Data were obtained from a cross-sectional survey of 355 households, key informant interviews, PRA-

This chapter was previously published non-open access with exclusive rights reserved by the Publisher. It has been changed retrospectively to open access under a CC BY 4.0 license and the copyright holder is "The Author(s)". For further details, please see the license information at the end of the chapter.

M. R. Motsholapheko (殴

Water Resources Management Program, Okavango Research Institute, University of Botswana, Maun, Botswana

e-mail: rmoseki@ub.ac.bw

B. N. Ngwenya

Ecosystems Services Program, Okavango Research Institute, University of Botswana, Maun, Botswana

e-mail: bntombi@ub.ac.bw

W. Leal Filho et al. (eds.), African Handbook of Climate Change Adaptation, https://doi.org/10.1007/978-3-030-42091-8_165-1 
based focus group discussions (FDGs), interviews with experts in various related fields, PRA workshop participant interviews, and literature review. There was high access to natural capital, and most households engaged in nature-based livelihood activities. Access to resources determined type of livelihood activities that households engaged in. However, there was no association between household exposure and/or susceptibility, and type of livelihood activities pursued by households. Household vulnerability to malaria was higher in remote and rural locations than in urban neighborhoods. Malaria prevention and vulnerability aversion programs need to be coupled with improvements in housing and wellbeing in the Okavango Delta and similar wetlands.

\section{Keywords}

Livelihoods $\cdot$ Malaria $\cdot$ Vulnerability $\cdot$ Wetlands

\section{Introduction}

In developing countries, access to natural resources largely determines human livelihoods and general well-being of households in many rural communities (Rebelo et al. 2010). Due to lack of access to various forms of capital including financial, physical, human, and social capital, and because of general poverty the dependence on natural resources has been increasing in wetland communities around the world. This is because wetlands act as sources of various forms of ecosystem services that support livelihoods. At the same time, wetlands provide suitable habitats for diseasecarrying organisms and therefore remain vector- and water-borne diseases endemic areas. Some vector-borne diseases such as malaria account for millions of human morbidity and deaths annually. For instance, the World Health Organization (WHO) reported that in 2018 malaria accounted for 228 million morbidity cases and 405,000 deaths globally, 94\% of which were in Africa (WHO 2019). Due to climate variability and change, the prevalence and virulence of vector-borne diseases (VBDs), including malaria, may increase (IPCC 2007). The challenges associated with malaria outbreaks include deaths of breadwinners in mostly poor households, which largely depend on the labor of their able-bodied members. Given that such mortalities often result in increased suffering of mostly women, children (WHO 2019), and other vulnerable groups, the fight against malaria requires concerted efforts on the part of governments, NGOs, communities, and other stakeholders to enhance access to prevention and treatment. Prevalence of malaria in tropical and subtropical regions including Africa, continues to overwhelm existing measures for prevention and treatment. This leads scientists and policymakers to assess existing forms of prevention and treatment with a view to developing effective means for combating malaria.

Various approaches have been adopted particularly in the prevention and treatment of malaria including (a) distribution of free insecticide-treated mosquito nets (ITNs) in rural communities, (b) use of preventive antimalarial medicines, (c) 
interior and exterior spraying, (d) awareness creation, and (e) educational campaigns. Most of these efforts have been supported by governments, NGOs, and global organizations including the World Health Organization. As a result, there is a general decline in the prevalence of malaria in developing countries. In some countries, where malaria prevalence had been recorded and often led to deaths, malaria has been successfully eradicated.

Botswana is one of the 21 countries which were identified by the WHO for malaria elimination by 2020 (WHO 2019). Botswana is also among eight southern African countries which formed the Elimination- 8 partnership aimed at eradicating cross-border malaria transmission by 2030 through collaborations and synchronization of policies and initiatives. At the national level, a rapid notification and response strategy was developed to eliminate malaria in hotspot areas, including the Ngamiland District in the Okavango Delta in Botswana (Chihanga et al. 2016).

Despite all these efforts, malaria remains pervasive in wetlands of developing countries, including Botswana, particularly among poor households. This calls for additional efforts to determine the general vulnerability of communities to malaria to improve general knowledge on factors that contribute to its persistence. This chapter is aimed at improving knowledge on household vulnerability to malaria in the Okavango Delta and similar areas around the world. Specifically, the chapter assesses (a) household access to water resources and (b) household vulnerability to malaria in Shakawe and Ngarange villages and the surrounding areas. The chapter is arranged as follows: the next section discusses the conceptual framework used, followed by environmental and socioeconomic context, research approach and data collection, the results on access to capital and household vulnerability, and finally, the section on discussion, conclusion, and implications for malaria policies in the Okavango Delta and other wetlands in similar socioeconomic and environmental conditions.

\section{Conceptual Framework}

This research was informed by the sustainable livelihood framework supplemented by the socio-ecological framework. These frameworks were selected for their wide use in microeconomic analyses on access to resources, rural livelihoods, and household vulnerability to shocks in developing countries. The frameworks differ in their approach to the household vulnerability context; the former views livelihood shocks as exogenous factors that are beyond household control, whereas the latter posits that shocks and household livelihoods are interlinked within the broad human-environment interactions (Berkes and Folke 1998; Ellis 2000). Both frameworks were influenced by the changing view on vulnerability as not just the biophysical nature of the shock but the state of the affected social unit as well (Wisner et al. 2004).

The sustainable livelihood framework provides an understanding of the broad concept of a livelihood, particularly the vulnerability context within a livelihood is constructed. In the sustainable livelihood framework, a livelihood can be defined as 
“... comprising of assets (natural, physical, human, financial, and social capital), the activities, and the access to these (mediated by institutions and social relations) that together determine the living gained by the individual or household" Ellis (2000, p. 30). The sustainable livelihood framework has some limitations because it does not cater for changes over time (Ellis 2000). It is nonhistoric because it takes current household access to resources as given, without looking at the origins and possible causes of current access conditions (Small 2007). Furthermore, it neither provides for tracing historical factors leading to current institutional structure, nor for understanding the nature of interactions between actors brought together by various interests and complying to set rules, norms, and practices (O'Laughlin 2002). For instance, it does not clearly show the role of the private sector as part of the organizations that mediate access to forms of capital. Furthermore, it does not provide adequate guidance on the analysis of institutions and the behavior of actors involved.

Another observation is that the vulnerability context in the sustainable livelihood framework does not consider the full context of shocks, trends, and seasonality, partly because it does not clearly show the position of the household itself. Although it considers both the negative and positive aspects of these processes, it does not clearly show how negative livelihood outcomes can exacerbate the impacts of shocks in the vulnerability context. This may be because it construes shocks as exogenous factors and therefore beyond household control (Ellis 2000). The sustainable livelihood framework is an integrating analytical tool which was never intended to be used in isolation (Farrington et al. 1999). The sustainable livelihood framework was supplemented with the socio-ecological framework to overcome some of its limitations. The socio-ecological framework was useful in locating the household construction of a livelihood within the broad human-environment interactions in which it occurs. In other words, it helped clarify the broad livelihood vulnerability context in the Okavango Delta. The socio-ecological complex or framework emanated from classical human ecology in the 1930s (Berkes and Folke 1998). It was influenced by the concept of resilience which has now become important for understanding complex relationships between human and other ecological systems (Folke 2001). The socio-ecological framework has been modified and used for analyzing human-environment interactions in developing countries and providing the basis for some contemporary vulnerability frameworks (Arntzen 1989; Adger 2006). This framework analyses rural development in terms of clusters of elements and interactions among clusters, which finally lead to a sustainable society or community (Arntzen 1989; Berkes and Folke 1998). It distinguishes four elements that characterize the socio-ecological linkages and interactions. These are population, organization, the environment, and technology at the micro-scale, with influencing factors at the macro-scales (regional, national, and global) (Arntzen 1989; Berkes and Folke 1998).

Understood in the context of this framework, the household as a human construct (illustrated in Fig. 1 below), and the livelihood as a subset of the household system, fall within the broad human-environment system. 


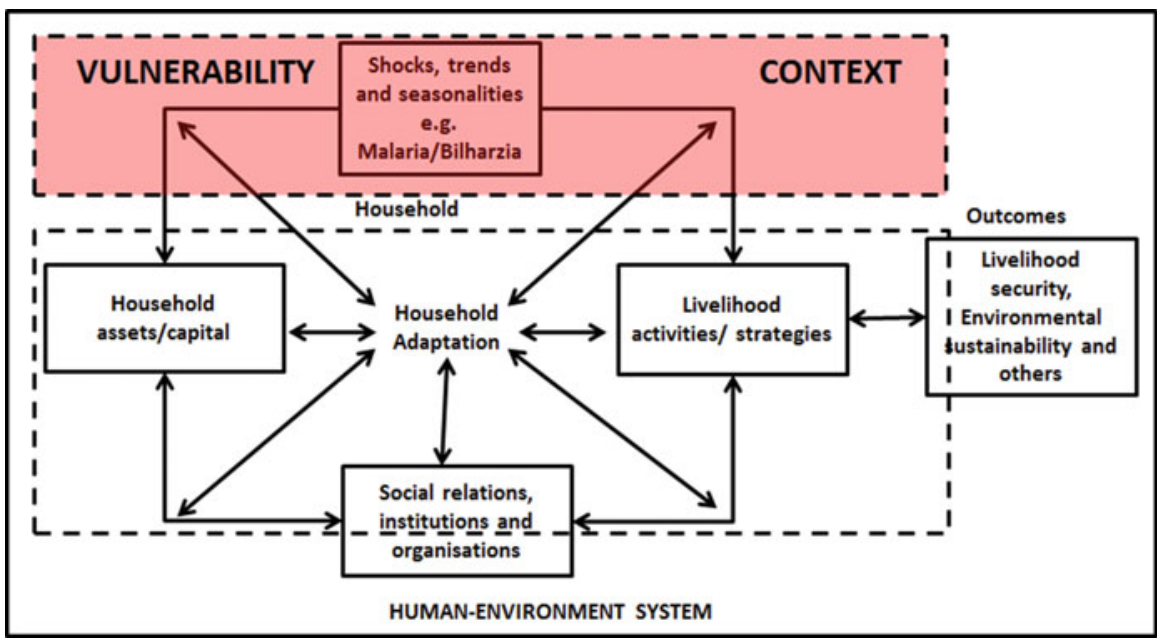

Fig. 1 Sustainable livelihood framework. (Source: Adapted from Ellis (2000, p. 30) with insights from Berkes and Folke (1998, p. 15))

Therefore, the impacts of a shock such as malaria, on a household livelihood and the household responses are part of the interface between the human and environment subsystems. In other words, it is acknowledged that livelihood shocks such as malaria are exogenous to a household because they fall beyond household control as posited by Ellis (2000). However, the effect of their impacts falls within household control depending on household exposure, susceptibility, and capacity to adapt. Therefore, such effects are part of the household vulnerability complex made up of the social (human) and biophysical (or ecological) aspects (Marshall et al. 2009). In the case of malaria endemicity in the Okavango Delta, household adaptation which is the inverse of vulnerability can therefore be viewed as the process and actions within a livelihood system occurring or being undertaken to positively influence or be influenced by livelihood security and environmental sustainability. This position is informed by the view that a livelihood is sustainable if it can adapt, be resilient, and therefore less vulnerable to shocks while not degrading the natural resource base (Scoones 1998).

Household adaptation to a livelihood shock such as malaria may occur at various dynamic levels influencing or being influenced by livelihood security and or environmental sustainability. It may also reduce the impacts of a shock on both livelihood assets and household livelihood activities, as well as the impacts of the institutions, social relations, and organizations, which modify or mediate access to household assets. Household actions to reduce vulnerability to malaria may also affect the setting up of livelihood activities with influence on the type of activity and location within which they may be undertaken. Of course, in case of maladaptation which has a positive effect in increasing vulnerability, the influence will be negative, leading to livelihood insecurity and environmental degradation. Of interest in this 
chapter is the household access to assets in the process of constructing livelihood activities and how such access exposes and makes households susceptible to malaria as a health risk. The chapter focuses on the vulnerability context as illustrated in Fig. 1 above.

\section{Okavango Delta: Environmental and Socioeconomic Context}

The Okavango Delta is an alluvial fan and a vast wetland well-renowned for its biodiversity, species richness, and prominence as a Ramsar Site, and 1000th UNESCO World Heritage Site in north-western Botswana. Due to its richness in flora and fauna, the Okavango Delta enhances dynamic livelihood systems within a semiarid environment of the southern African Kalahari plains. The Okavango Delta and related floodplains, at an altitude of $900 \mathrm{~m}$ above sea-level, within a lowphysiographic zone given the generally flat terrain, and daily temperatures ranging from $12{ }^{\circ} \mathrm{C}$ to $40{ }^{\circ} \mathrm{C}$ provide a suitable habitat for the anopheles mosquito (Anopheles arabiensis). Rural communities found in many settlements around the Delta fringes as they depend on the natural resources in the form of flora such as papyrus, riverine reeds, grasses, and others, as well as faunal species including fish, birds, and small game.

The specific research sites were the villages of Shakawe and Ngarange in the Okavango sub-District of Ngamiland District. Ngamiland West, a Ministry of Health designated area which largely covers the Okavango sub-District, is among the poorest regions in the country with $47.3 \%$ of people below the poverty datum line compared to the national figure of 20.7\% (Statistics Botswana 2011). Ngamiland West is a malaria-endemic area due to the high persistence of this disease in many of its villages. HIV/AIDS prevalence in the Ngamiland District is also high (18\%), compared to the national average of $17.6 \%$ (Central Statistics Office 2009) (Fig. 2).

Shakawe and Ngarange villages are in an area commonly referred to as the panhandle, which is made up of the Okavango River as it enters Botswana from the Kavango Region of Namibia. Shakawe village has a population of 6693 people and Ngarange has 998 people. The population structures of these two villages (Fig. 3) depict a wide base in the young age groups compared to advanced age groups; the patterns that are typical of population structures found in developing countries.

However, there appears to be an anomaly in that the population pyramids in these villages have a narrowed base particularly in the infant cohorts and under-five age group, which is indicative of low fertility and possibly high mortality in these age groups. This is a logical observation in that due to high prevalence of HIV/AIDS, women may tend to postpone their engagement in sexual activity, or totally abstain from sex to avoid repeat infections and/or opt for effective birth prevention methods (Lewis et al. 2004). Due to illness and the impacts of opportunistic diseases, HIV/ AIDS also has adverse effects on fertility (Ross et al. 1999). Infant and under-five mortality is generally higher in communities with high HIV/AIDS prevalence than in 


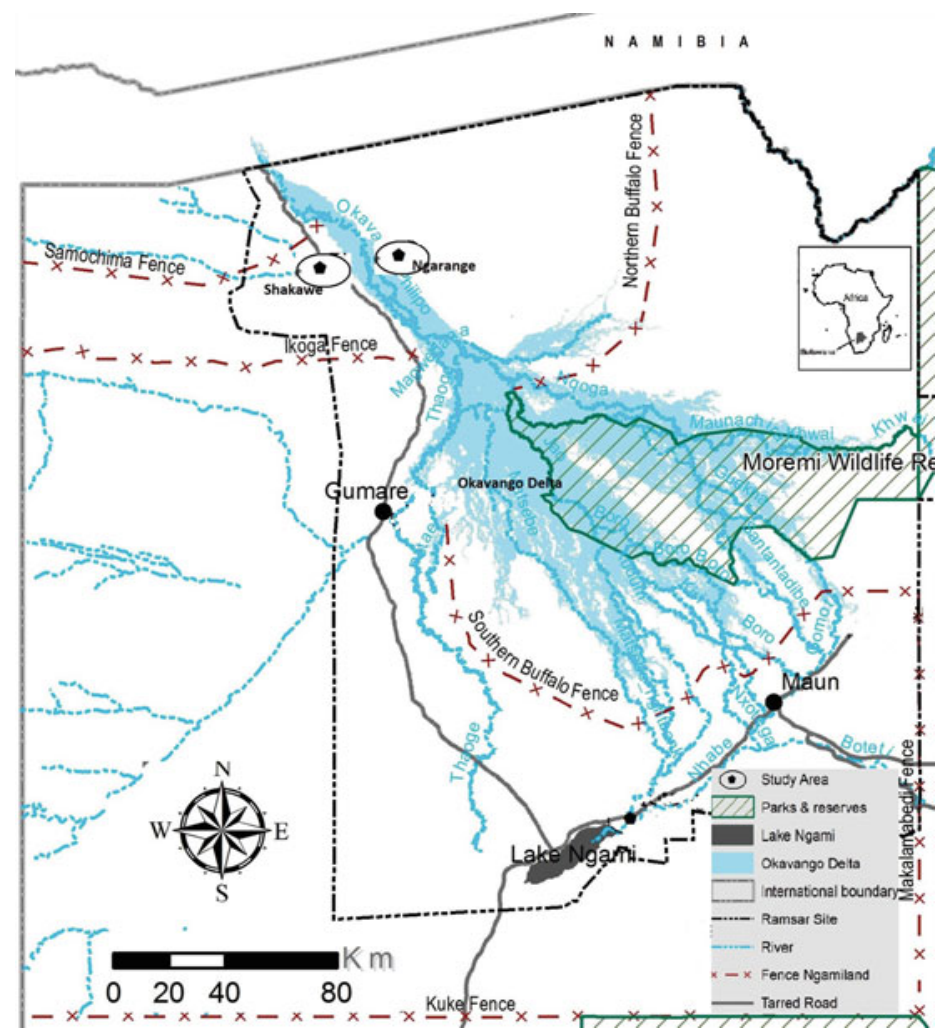

Fig. 2 Map showing the Okavango Delta and the study villages. (Source: ORI GIS Lab)

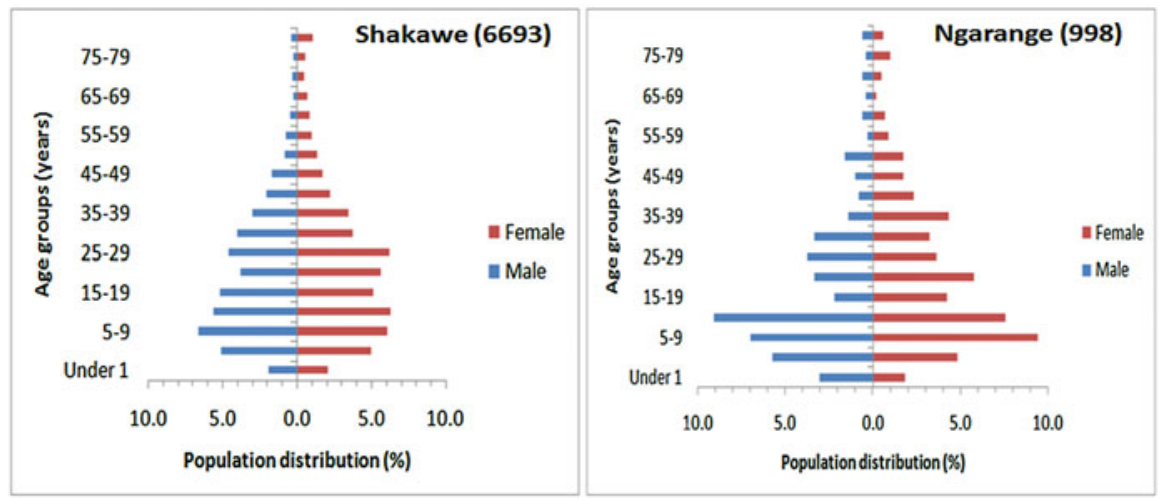

Fig. 3 Population structure in Shakawe and Ngarange villages 
those with low prevalence and this may have been contributed to the narrow pyramid base in these two villages. From the foregoing, households in Shakawe and surrounding villages including Ngarange may be vulnerable to other diseases including malaria.

Shakawe has been identified as a malaria hotspot in Botswana mainly due to the high number of confirmed cases in this village. Ngarange has been observed to have low confirmed cases compared to other settlements in the same area. These two villages were selected to understand this apparent contrast and general dynamics surrounding household vulnerability to malaria in the Okavango Panhandle and the Okavango Delta in general.

\section{Research Approach and Data Collection}

A convergent parallel mixed-method approach was adopted; it involved the concurrent use of qualitative and quantitative methods of data collection and analysis. This approach made it possible to exhaustively obtain information from the various methods used and substantively confirm outcomes through triangulation. It was also noninterventional given that no further action was taken in treating those infected with malaria; affected individuals received treatment from local health clinics in the respective villages.

Secondary data were obtained through desktop searches in the World Wide Web and from the review of published and unpublished sources including journal articles, global and regional health (and other) organizations' reports, and the national health policy and strategy documents. Primary data were obtained, (a) through a participatory rural appraisal (PRA) methodology which included key informant interviews and PRA-based focus group discussions, (b) through a household survey and informal discussions with community members, and (c) from interviews with various stakeholders including officers in local health clinics, the district office in Maun, the sub-District main office in Gumare, and from the Ministry of Health head office in Gaborone.

\section{Participatory Rural Appraisal (PRA) Workshop}

A PRA workshop was held on June 25-27, 2014 in Shakawe with the aim to create project awareness, stakeholders' involvement, and participation in the project, and to collect baseline data on key areas that required further scientific enquiry. In the latter aim, the researchers were able to document community knowledge on livelihoods, the social, environmental, and climate change factors that influence household vulnerability to vector-borne diseases including malaria. Stakeholders including traditional leaders, traditional health practitioners, representatives of various village committees, modern medical practitioners, government health officers, and nongovernmental organizations' (NGOs) representatives were invited to the workshop. The criteria for selecting other members of the community included (a) being adult 
women and men above the age of 18 years, (b) having lived in the locality for 10 years or more, and (c) being knowledgeable on vector-borne diseases. A total of 40 people, 25 (63\%) from Shakawe, and 15 (38\%) from Ngarange were invited; the total consisted of $13(32 \%)$ female and $27(68 \%)$ male. Given the diversity of stakeholders and level of representation, the PRA workshop provided opportunities for interviews with the attendants individually, as key informants, discussants in focus group discussions, and as participants in a plenary.

\section{Household Survey}

The household survey was undertaken following a stratified sampling of households. Information on malaria occurrence was first obtained from the local clinics in the villages of Shakawe and Ngarange. Using such information, village wards were identified and differentiated according to high, medium, and low number of malaria cases. Village wards were then randomly selected from the broad categories of high, medium, and low malaria cases. In Shakawe, a total of seven out of fourteen wards were selected. Although the same stratification criteria of high, medium, and low malaria cases were used in Ngarange, given the small size of the village, all wards were selected. After the selection of wards in both villages, all households in the selected wards were listed. From a list of households in all the selected wards, households were selected proportionate to size of ward. In Shakawe, a total of 877 households were listed in the seven wards, whereas in Ngarange 300 households were listed in the four wards, therefore some overall total of 1177 households were listed in these two villages. The sample size in the two villages was calculated at $95 \%$ confidence interval with margin of error of plus/minus five (+/-5). An overall sample of 355 households (266 in Shakawe and 89 in Ngarange) was selected in the two villages (Table 1).

Table 1 Number of households listed and sampled in various wards of Shakawe and Ngarange villages

\begin{tabular}{l|l|l|l}
\hline \multirow{2}{*}{ Village } & Ward & $\begin{array}{l}\text { Listed households } \\
(N=1177)\end{array}$ & $\begin{array}{l}\text { Sampled households } \\
(n=355)\end{array}$ \\
\hline Shakawe $(n=266)$ & Mabudutsa & 29 & 9 \\
\cline { 2 - 4 } & Matomo & 55 & 17 \\
\cline { 2 - 4 } & Ukusi & 83 & 25 \\
\cline { 2 - 4 } & Ndumbakatadi & 163 & 49 \\
\cline { 2 - 4 } & Saoshoko & 178 & 54 \\
\cline { 2 - 4 } & Diseta & 140 & 42 \\
\hline \multirow{2}{*}{ Ngarange $(n=89)$} & Gauxa & 229 & 70 \\
\hline & Modubana & 103 & 30 \\
\cline { 2 - 4 } & Newtown & 48 & 14 \\
\cline { 2 - 4 } & Mukumbe & 107 & 33 \\
\cline { 2 - 4 } & Sekandeko & 42 & 12 \\
\hline
\end{tabular}


A questionnaire comprising structured and semistructured questions were developed. It had sections on (a) household demographic and socioeconomic characteristics, (b) types of livelihood activities, (c) access to and ownership of assets or capital, (d) malaria prevention and coping strategies and other sociocultural variables. Data on household characteristics, livelihood types, and malaria prevention and coping strategies were captured through open- and close-ended questions. Data on access to capital were obtained through several proxy indicators. For example, access to financial capital was measured using questions on whether (or not) a household had access to cash, credit, and insurance, and access to physical capital was measured through questions on ownership of assets such the plowing equipment, vehicles, telecommunication equipment, and so on.

Various forms of capital were measured using different units; therefore, composite unitless indices similar to the UNDP's human development index were developed to consolidate the various measurement units. Data on household adaptive capacity, susceptibility, and exposure were also captured and transformed into unitless indices. Vulnerability was then calculated using a composite index, being a function of exposure less adaptive capacity, multiplied by susceptibility. Details of the techniques used are described in detail in Hahn et al. (2009), Motsholapheko et al. (2011), and UNDP (1990), so they will not be repeated in this paper. The questionnaire was administered through face-to-face interviews with household heads, their spouses, and adult representatives. The survey data collection was undertaken in the period October 27 to November 6, 2015, in the two villages of Shakawe and Ngarange.

\section{Access to Water Resources in Shakawe and Ngarange}

Results from the survey (Fig. 4) reflected generally similar patterns of access to capital in the two villages. Access to natural capital was higher than that of other capital types in both Ngarange and Shakawe. However, specific differences can be identified; households in Ngarange had slightly higher access to natural capital than those in Shakawe; the index values were 0.67 and 0.61 , respectively. Worth noting is that access index values are all above 0.5 and edge toward the value of one which is the maximum. This result is not surprising given that Ngarange has a small population and the village is remotely located on the eastern side of the river which has vast floodplains than in the western escarpment where Shakawe is located. The proportions of households who stated that they had unimpeded access to land, water, forest, and aquatic resources were higher in Ngarange, ranging from $63 \%$ to $75 \%$, compared to Shakawe where these proportions ranged from $56 \%$ to $72 \%$. In wetlands, such as the Okavango Delta, rural communities depend on natural resources to make a living.

Ngarange households had slightly higher access to financial capital than their counterparts in Shakawe with index values of 0.5 and 0.36 , respectively. This was a counter-intuitive result given that Shakawe, as the main commercial center in the area, is more urbanized than Ngarange. A further assessment of household characteristics and livelihood activities revealed that most households in Shakawe were 


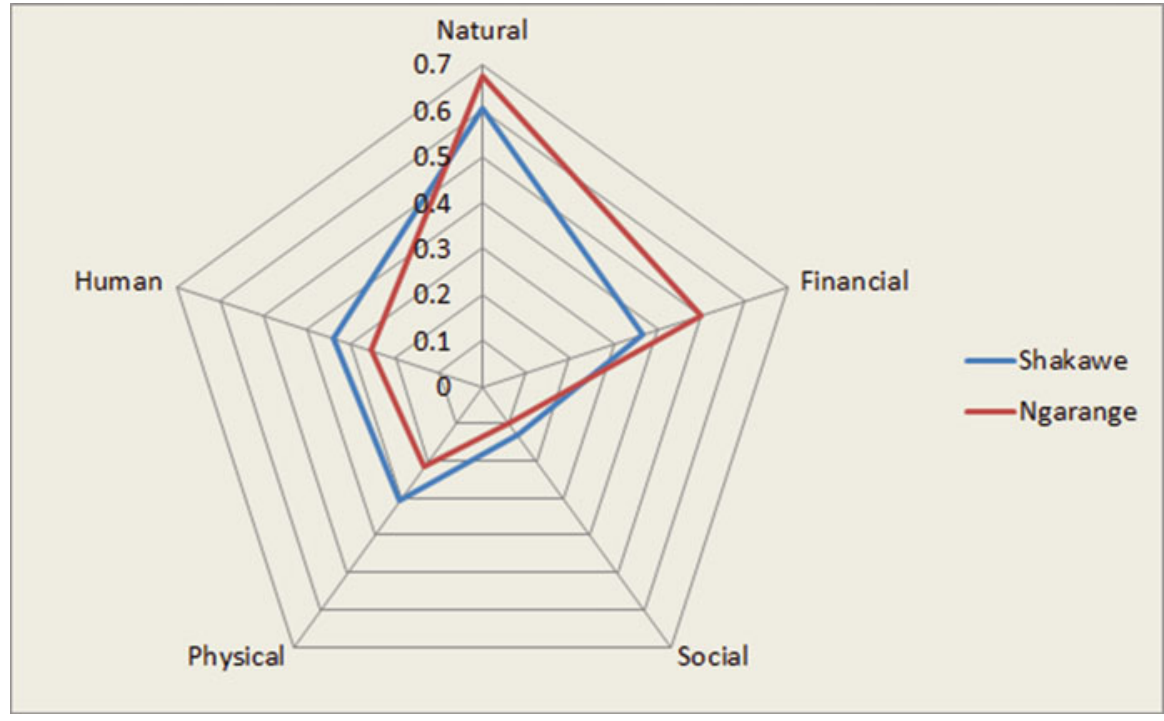

Fig. 4 Household access to resources in Shakawe and Ngarange villages

de jure female-headed (57\%) whereas male-headed households accounted for $33 \%$ and the rest were de facto female-headed at $10 \%$ (De jure female-headed households are those that are directly headed by females, whereas de facto female are those headed by females in the absence of the substantive male head (Motsholapheko et al. 2011).). Conversely, most households in Ngarange were male-headed (44\%), the remaining being de jure (25\%) and de facto (31\%) femaleheaded. Interviews with experts on livelihoods and social development in the area revealed that although Shakawe is more urbanized than most settlements around it, the village could have experienced retarded development related to ownership of land. Large portions of undeveloped land in the village belong to a few individuals whose capacity to develop may either be limited or depends on self-interest and monopolistic tendencies. A further scrutiny of the above indices for Ngarange (0.5) and Shakawe (0.36) indicates a generally low access to financial capital in both villages, given that households have access values of up to half or less than the maximum value of one.

Access to physical, human, and social capital was higher in Shakawe than in Ngarange. Index values were 0.31 and 0.21 for physical capital, 0.34 and 0.25 for human capital, and 0.13 against 0.1 for social capital in Shakawe and Ngarange, respectively. A key observation here is that although Shakawe village households have a slight edge over those in Ngarange, all the above values are very low ranging from 0.26 to 0.36 which reveals very low access compared to a maximum value of one. In terms of ranking, access to natural capital would be the highest followed by financial, human, physical, and social capital in that order. Social capital was least accessed by households in both villages. Key informant interviews have revealed 
that access to social capital in these villages was adversely affected by loss of culture, breakdown in family ties, individualism, and general lack of cooperation within the village community.

\section{Household Vulnerability to Malaria in Shakawe and Ngarange}

Results from PRA-based key informant interviews (Table 2) revealed a general awareness among interviewees that malaria exposure was dominant among some social groups than others within their communities.

Most key informant interviewees (78\%) stated that under-five children were the most exposed to malaria whereas safari operators were the least exposed, being stated by $35 \%$ of the interviewees. According to key informants, the top five most affected social groups were under-five children, primary school, commercial fishers, pregnant women, hook and line fishers, and river reed/grass harvesters. Commercial fishers and pregnant women were stated by an equal proportion of key informants at $52 \%$. The various social groups stated above are linked to the types of livelihood activities they engage in, as well as their levels of possible susceptibility to malaria given their physical condition. For example, under-five children and pregnant women are known to be more susceptible to most diseases due to their physical condition (Bates et al. 2004).

Key informant interviewees also perceived that some livelihood activities such as commercial fishing and river grass harvesting were high-risk activities for malaria exposure; they were stated by $62.5 \%$ and $50 \%$ of the interviewees, respectively (Table 3). The top five livelihood activities stated by interviewees as likely to expose households and community members to malaria were commercial fishing, grass harvesting, reed harvesting, livestock herding, hook and line fishing, and arable farming.

Table 2 Key informants' perceptions on social groups and vulnerability to malaria

\begin{tabular}{l|l|l}
\hline Social group & $\begin{array}{l}\text { Proportion of key informants } \% \\
(n=40)\end{array}$ & Top five social groups \\
\hline Children $<5$ years & 78 & 1. Children $<5$ \\
\hline $\begin{array}{l}\text { Primary school } \\
\text { children }\end{array}$ & 58 & 2. Primary school children \\
\hline Pregnant women & 52 & $\begin{array}{l}\text { 3. Commercial fishers and pregnant } \\
\text { women }\end{array}$ \\
\hline Commercial fishers & 52 & 4. Hook and line fishers \\
\hline $\begin{array}{l}\text { Hook and line } \\
\text { fishers }\end{array}$ & 50 & 5. Reed/grass harvesters \\
\hline $\begin{array}{l}\text { Reed/grass } \\
\text { harvesters }\end{array}$ & 48 & \\
\hline Polers & 40 & \\
\hline Cattle herders & 38 & \\
\hline Safari operators & 35 & \\
\hline
\end{tabular}


Table 3 Proportions of key informants and their perceptions on level of risk of malaria infection and related livelihood activities

\begin{tabular}{l|l|l|l|l}
\hline \multirow{2}{*}{ Livelihood activities } & \multicolumn{4}{|l}{ Proportion of key informants (\%) by perception of level of risk $(n=40)$} \\
\cline { 2 - 5 } & High & Medium & Low & Don't know \\
\hline Commercial fishing & 62.5 & 22.5 & 10 & 5 \\
\hline Grass harvesting & 50 & 20 & 15 & 15 \\
\hline Reed harvesting & 47.5 & 17.5 & 25 & 10 \\
\hline Livestock herding & 45 & 7.5 & 32.5 & 15 \\
\hline Hook and line & 42.5 & 17.5 & 32.5 & 7.5 \\
\hline Arable farming & 42.5 & 22.5 & 25 & 10 \\
\hline Tourist poling & 40 & 15 & 22.5 & 22.5 \\
\hline Basket Fishing & 37.5 & 22.5 & 27.5 & 12.5 \\
\hline Tswii harvesting & 37.5 & 12.5 & 32.5 & 17.5 \\
\hline Tour guiding & 35 & 15 & 15 & 35 \\
\hline Molapo farming & 30 & 12.5 & 10 & 47.5 \\
\hline Basket weaving & 20 & 12.5 & 50 & 17.5 \\
\hline
\end{tabular}

Basket weaving was perceived by $50 \%$ of interviewees as less likely to expose households and community members to malaria. Furthermore, molapo farming was one of the activities viewed as less likely to expose households and community members to malaria being stated by $30 \%$ interviewees. However, most interviewees (47.5) indicated that they did not know the likely level of exposure to malaria for molapo farming households and community members. This could be due to insufficient knowledge on molapo farming among Shakawe and Ngarange communities. Studies have indicated that molapo farming is not widely practiced in these communities compared to their counterparts in the mid- and lower parts of the Okavango Delta.

Results from the socioeconomic survey (Fig. 5 below) indicated that the top five livelihood activities undertaken by households in Shakawe were river grass harvesting in which $60 \%$ of households were involved, reed harvesting $(58 \%)$, dryland/rain-fed arable farming (49\%), livestock farming (35\%), and tswii (waterlily or Nymphaea tuber) harvesting (30\%).

These results corroborated key informant interview results on four of the five livelihood activities. Although hook-and-line fishing and commercial fishing were indicated as possible high-risk activities, the socioeconomic survey indicated that these livelihood activities were undertaken by a low proportion of households at $15 \%$ and $4.8 \%$, respectively.

\section{Household Exposure, Susceptibility, and Adaptive Capacity}

Survey results (Fig. 6) revealed that households in Ngarange village had higher exposure to malaria (0.5) than their counterparts in Shakawe (0.34). These results are quite realistic in that Ngarange village is located near a vast floodplain where water flow is limited compared to Shakawe, which is located along an escarpment. 


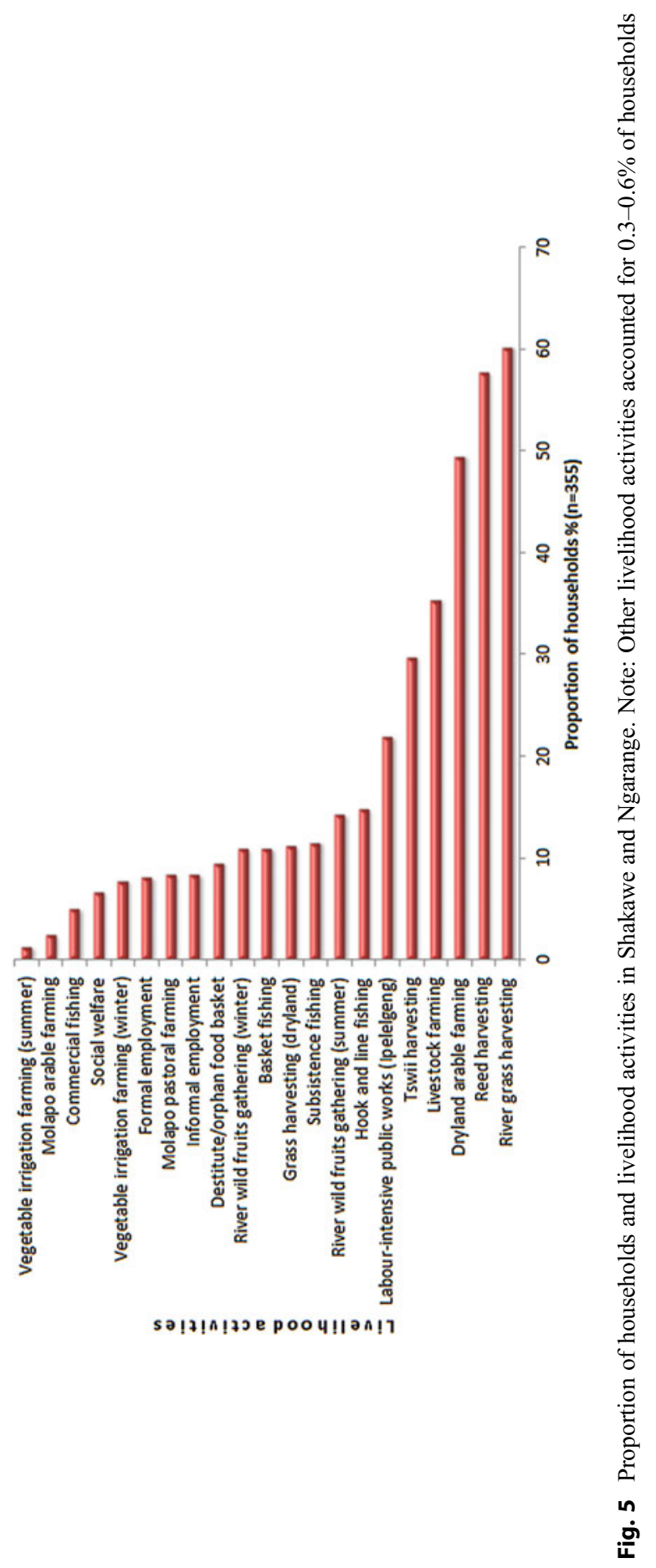




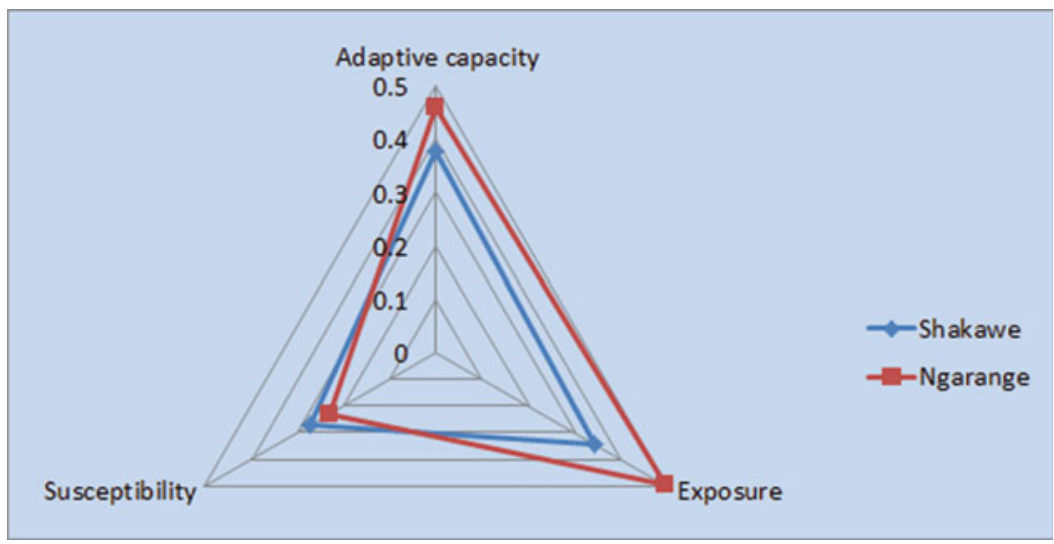

Fig. 6 Village-level susceptibility, adaptive capacity and exposure to malaria

Ngarange households also had higher adaptive capacity (0.46) than those in Shakawe (0.38). Worth noting is that household exposure (0.5) to malaria in Ngarange was higher than adaptive capacity (0.46) meaning that within the village, households could not adequately prevent malaria transmission. In Shakawe, households had higher adaptive capacity (0.38) than exposure (0.34) meaning that they could prevent malaria transmission.

In both villages, the overall household susceptibility to malaria was lower than both adaptive capacity and exposure. Ngarange had a slightly lower susceptibility value $(0.23)$ than Shakawe $(0.27)$, which indicates that households in both villages had almost the same level of susceptibility to malaria. A further assessment of household exposure, adaptive capacity, and susceptibility within these two villages indicates that households in five out of seven wards in Shakawe had higher adaptive capacity than exposure to malaria. The five wards of Diseta, Matomo, Ndumbakatadi, Mabudutsa II, and Saoshoko had adaptive capacity that exceeded exposure values, whereas in the two wards of Gauxa and Ukusi, the exposure values of 0.39 and 0.44 were higher than the respective adaptive capacity values of 0.35 and 0.28 (Fig. 7).

This indicates that households in Gauxa and Ukusi wards of Shakawe were not adequately adaptable to malaria than their counterparts in the other five wards. Household susceptibility in to malaria in four of the seven wards of Shakawe was higher than both exposure and adaptive capacity. The susceptibility values in these wards were 0.65 or higher compared to both exposure and adaptive capacity values that ranged from 0.27 to 0.44 .

In Ngarange, household exposure was higher than both adaptive capacity and susceptibility to malaria in all wards except in Mukumbe Ward, which had a susceptibility value of 0.63 that was higher than both adaptive capacity and exposure. These results indicate that households in all the wards in Ngarange are not adaptable and as such vulnerable to malaria, particularly Mukumbe Ward which had higher susceptibility than the other wards. 


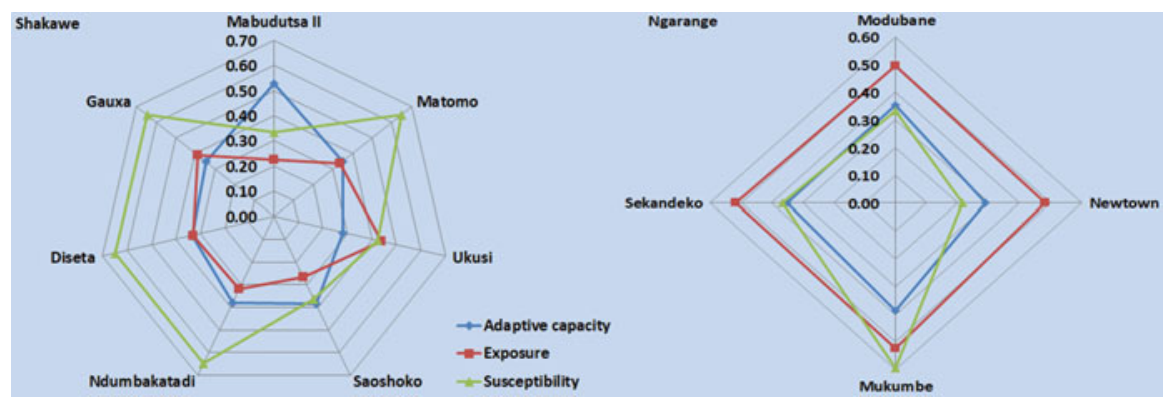

Fig. 7 Household adaptive capacity, susceptibility and exposure to malaria in Shakawe and Ngarange

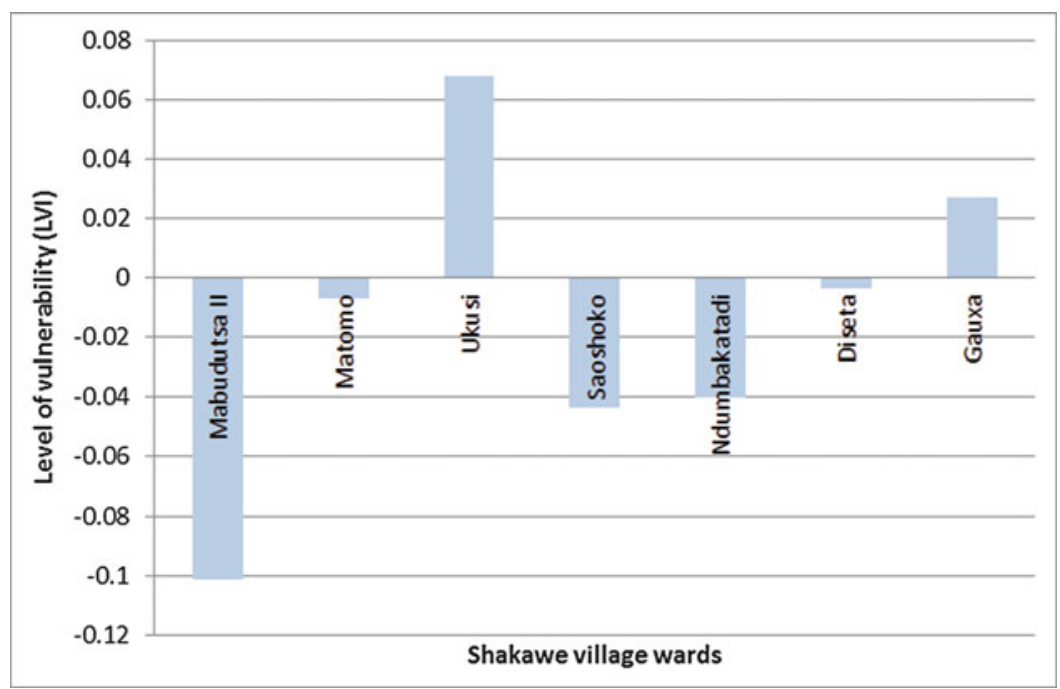

Fig. 8 Level of household vulnerability (LVI) by ward in Shakawe

The overall livelihood vulnerability indices for these villages were -0.0092 for Shakawe and 0.0088 for Ngarange, which confirms the above suggestion that households in Ngarange were not adequately adaptable and therefore vulnerable to malaria whereas their counterparts in Shakawe were not vulnerable. A further analysis indicates that households in Mabudutsa II ward of Shakawe had the lowest vulnerability score of -0.101 (Fig. 8 ), which indicates that they could withstand the impacts of malaria much better than their counterparts in other wards.

The other four wards of Saoshoko $(-0.043)$, Ndumbakatadi $(-0.04)$, Matomo $(-0.007)$, and Diseta $(-0.003)$ also had low vulnerability scores. The two wards of Ukusi (0.068) and Gauxa (0.027) were vulnerable to malaria given that they had positive values. The vulnerability scores for the two wards of Matomo and Diseta 


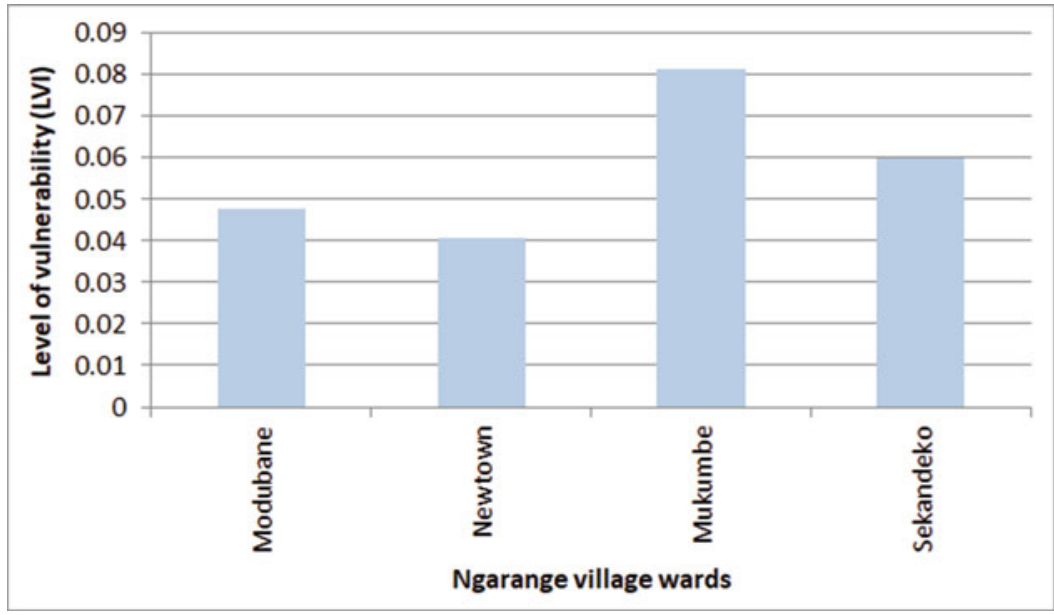

Fig. 9 Level of household vulnerability (LVI) by ward in Shakawe

were close to the value of zero, which indicates that even though these two wards were not vulnerable, any slight decline in adaptive capacity or increase in exposure to malaria may render households in these two wards vulnerable to malaria.

In Ngarange, all wards were vulnerable to malaria, Mukumbe Ward having the highest vulnerability value of 0.08 whereas Newtown Ward had the lowest vulnerability at 0.04 (Fig. 9).

A further analysis indicated that households in the two most vulnerable wards of Mukumbe and Sekandeko in Ngarange were the most susceptible and least adaptable to malaria.

\section{Discussion and Conclusion}

This chapter assessed household access to water resources as well as vulnerability to malaria in the Okavango Delta. The results indicate that household access to natural capital was much higher than that of other types of capital. Households mostly engaged in nature-based livelihood activities such as rain-fed arable agriculture, livestock, and the harvesting of aquatic reed, river grass, and tswii (nymphaea). Most Ngarange households engaged in nature-based livelihoods than their counterparts in Shakawe village, which was relatively more urbanized than Ngarange. Social capital was the least accessed of all the five forms of capital. It has also been demonstrated that households in Ngarange were more vulnerable to malaria than their counterparts in Shakawe and that this vulnerability emanated from high-household exposure mainly due to low capacity to adapt to malaria than their counterparts in Shakawe.

Due to high access to natural capital compared to other capital forms, households engaged in nature-based livelihood activities. This is typical of most rural communities in developing countries, particularly those residing in wetlands of sub-Saharan 
Africa (Babulo et al. 2008; Rebelo et al. 2010; Angelsen et al. 2014). As earlier indicated in the conceptual framework, households' choice of livelihood activity depends on access to capital such that the most accessed type of capital may determine the main livelihood activity in any livelihood portfolio (Ellis 2000; Berkes and Folke 1998).

Access to social capital was lower than that of other capital forms contrary to expectation that this form of capital is higher in rural communities than in urban settings. Key informants attributed this low access to social capital to loss of culture, breakdown in family ties, a rise in individualism and general lack of cooperation within the village community. Low access to social capital may have adverse impacts on the well-being of households given that cultural diversity, social cohesion, and network are critical components of social sustainability (Munasinghe 2000).

Households in Ngarange were found to be more vulnerable to malaria than their counterparts in Shakawe. This vulnerability could be attributed to high exposure to malaria partly due to type of housing, and household practices relating to malaria prevention. Some studies have posited that malaria transmission is related to type of housing, and with increased urbanization and change of housing structure malaria transmission is likely to decrease in sub-Saharan Africa (Saugeon et al. 2009; Parnell and Walawege 2011). Household livelihood activities (such as agriculture) and practices have also been found to be confounding factors for malaria transmission, in Africa and Southeast Asia even in urban communities (Klinkenberg et al. 2008). Effectively, malaria transmission directly relates to type of housing, preventive measures, and practices relating to mosquito bites avoidance (Tusting et al. 2016).

Vulnerable groups such as pregnant women, under-five children, and the elderly require targeted programs with emphasis on availing the means to prevent malaria transmission. There is a need for long-term, sustained prevention, and control to reduce and/or eliminate malaria in the Okavango Delta and Botswana, in general.

\section{References}

Adger WN (2006) Vulnerability. Glob Environ Chang 16:268-281

Angelsen A, Jagger P, Babigumira R, Belcher B, Hogarth NJ, Bauch S, Rner JB, Smith-Hall C, Wunder S (2014) Environmental income and rural livelihoods: a global-comparative analysis. World Dev 64:S12-S28

Arntzen J (1989) Environmental pressure and adaptation in rural Botswana. PhD thesis, Vrije University of Amsterdam, Amsterdam

Babulo B, Muys B, Nega F, Tollens E, Nyssen J, Deckers J, Mathijs E (2008) Household livelihood strategies and forest dependence in the highlands of Tigray, northern Ethiopia. Agric Syst 98:147-155

Bates I, Fenton C, Gruber J, Lalloo D, Lara AM, Squire SB, Theobald S, Thomson R, Tolhurst R (2004) Vulnerability to malaria, tuberculosis, and HIV/AIDS infection and disease. Part 1: determinants operating at individual and household level. Lancet Infect Dis 4:267-277 
Berkes F, Folke C (1998) Linking social and ecological systems for resilience and sustainability. In: Berkes F, Folke C, Colding J (eds) Linking social and ecological systems: management practices and social mechanisms for building resilience. Cambridge University Press, Cambridge

Central Statistics Office (2009) 2008 Botswana AIDS impact survey III statistical report. Central Statistics Office, Gaborone

Chihanga S, Haque U, Chanda E, Mosweunyane T, Moakofhi K, Jibril HB, Motlaleng M, Zhang W, Glass GE (2016) Malaria elimination in Botswana, 2012-2014: achievements and challenges. Parasit Vectors 9:99. https://doi.org/10.1186/s13071-016-1382-z

Ellis F (2000) Rural livelihood diversity in developing countries. Oxford University Press, Oxford

Farrington J, Carney D, Ashley C, Turton C (1999) Sustainable livelihoods in practice: early applications of concepts in rural areas. Natural resources perspectives paper number 42 . Overseas Development Institute, London

Folke C (2001) Socio-ecological resilience and behavioral responses. http://www.beijer.kva.se/ publications/pdf-archive/Disc155.pdf. Accessed 07 June 2018

Hahn MB, Riederer AM, Foster SO (2009) The livelihood vulnerability index: a pragmatic approach to assessing risks from climate change variability and change - a case study in Mozambique. Glob Environ Chang 19:74-88

Intergovernmental Panel on Climate Change [IPCC] (2007) Climate change 2007: impacts, adaptation and vulnerability. Contribution of working group II to the fourth assessment report of the Intergovernmental Panel on Climate Change. Cambridge University Press, Cambridge, UK

Klinkenberg E, McCall PJ, Wilson MD, Amerasinghe FP, Donnelly MJ (2008) Impact of urban agriculture on malaria vectors in Accra, Ghana. Malar J 7:151

Lewis JJC, Ronsmans C, Ezeh A, Gregson S (2004) The population impact of HIV on fertility in sub-Saharan Africa. AIDS 18(2):S35-S43

Marshall NA, Marshall PA, Tamelander J, Obura D, Malleret-King D, Cinner JE (2009) A framework for social adaptation to climate change: sustaining tropical coastal communities and industries. IUCN, Gland

Motsholapheko MR, Kgathi DL, Vanderpost C (2011) Rural livelihoods and household adaptation to extreme flooding in the Okavango Delta, Botswana. Physics and Chemistry of the Earth 36:984-995

Munasinghe M (2000) Development, equity and sustainability (DES) in the context of climate change. Guidance Papers on the Cross Cutting Issues of the Third Assessment Report of the IPCC, 69-90

O'Laughlin B (2002) Proletarianization, agency and changing rural livelihoods: forced labor and resistance in colonial Mozambique. J South Afr Stud 28(2):511-530

Parnell S, Walawege R (2011) Sub-Saharan African urbanization and global environmental change. Glob Environ Chang 21(1):12-20

Rebelo LM, McCartney M, Finlayson C (2010) Wetlands of sub-Saharan Africa: distribution and contribution of agriculture to livelihoods. Wetl Ecol Manag 18(5):557-572

Ross A, Morgan D, Lubega R, Carpenter LM, Mayanja B, Whitworth JA (1999) Reduced fertility associated with HIV: the contribution of pre-existing subfertility. AIDS 13:2133-2141

Saugeon C, Baldet T, Akogbeto M, Henry MC (2009) Will climate and demography have a major impact on malaria in sub-Saharan Africa in the next 20 years? Med Trop 69(2):203-207

Scoones I (1998) Sustainable rural livelihoods: a framework for analysis. IDS working paper 72. Institute of Development Studies, London

Small L (2007) The sustainable rural livelihoods approach: a critical review. Can J Dev Stud 28:27-38

Statistics Botswana (2011) Botswana core welfare indicators (poverty) survey of 2009/10 preliminary results. Statistics Botswana, Gaborone

Tusting LS, Rek J, Arinaitwe E, Staedke SG, Kamya MR, Cano J, Bottomley C, Johnston D, Dorsey G, Lindsay SW, Lines J (2016) Why is malaria associated with poverty? Findings from a cohort study in rural Uganda. Infect Dis Poverty 5:78

United Nations Development Program [UNDP] (1990) Human development report. UNDP, New York 
Wisner B, Blaikie P, Cannon T, Davis I (2004) At risk: natural hazards, people's vulnerability and disasters, 2nd edn. Routledge, London

World Health Organization [WHO] (2019) World malaria report 2019. World Health Organization, Geneva

Open Access This chapter is licensed under the terms of the Creative Commons Attribution 4.0 International License (http://creativecommons.org/licenses/by/4.0/), which permits use, sharing, adaptation, distribution and reproduction in any medium or format, as long as you give appropriate credit to the original author(s) and the source, provide a link to the Creative Commons license and indicate if changes were made.

The images or other third party material in this chapter are included in the chapter's Creative Commons license, unless indicated otherwise in a credit line to the material. If material is not included in the chapter's Creative Commons license and your intended use is not permitted by statutory regulation or exceeds the permitted use, you will need to obtain permission directly from the copyright holder.

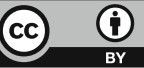

